\title{
Microwave Absorbing Properties of NiZnCu Ferrite and Polychloropren Composites
}

\author{
Priscila Richa ${ }^{1, *}$, Roberto Costa Lima", Ana Paula Santiago de Falco¹, Ana Paula da Silva, Elvia Leal², \\ Ana Cristina Figueiredo de Melo Costa²
}

Richa P (D) https://orcid.org/0000-0002-1950-4781

Lima RC (D) https: / / orcid.org/0000-0001-5636-9518

Falco APS (D) https://orcid.org/0000-0002-8574-8805

\section{How to cite}

Richa P; Lima RC; Falco APS; Silva AP; Leal E; Costa ACFM (2019) Microwave Absorbing Properties of Nizncu Ferrite and Polychloropren Composites. J Aerosp Technol Manag, 11, Special Edition: 27-32. https://doi.org/10.5028/jatm. etmq.85

ABSTRACT: Radar-absorbing materials (RAMs) have been used in military applications for several decades to reduce radar detection of vessels and aircrafts. In the present work, the performance of $\mathrm{Ni}_{035} \mathrm{Zn}_{0.35} \mathrm{Cu}_{\mathrm{O}_{3}} \mathrm{Fe}_{2} \mathrm{O}_{4}$ ferrite as a RAM is investigated. The ferrite was firstly synthesized by combustion reaction and then calcinated at $1200{ }^{\circ} \mathrm{C}$ for $1 \mathrm{~h}$. Composites were prepared with 80:20, 70:30 and 60:40 concentrations in weight of ferrite:polychloroprene. The X-ray diffraction (XRD) analysis showed a single phase ferrite formation and the scanning electron microscopy (SEM) analysis of the composites showed a good dispersion of the ferrite in the polychloroprene matrix. The electromagnetic (EM) characterization of the composites revealed that the EM attenuation is mainly attributed to magnetic losses observed in the material. The 80:20 composite achieved the best performance and presented a reflectivity of $-26.7 \mathrm{~dB}$ at $10.2 \mathrm{GHz}$.

KEYWORDS: Ferrites; Combustion; Microwave; Radar.

\section{INTRODUCTION}

Radar-absorbing materials (RAMs) are capable of attenuating the incident electromagnetic wave through the dissipation of the absorbed energy in the form of heat, due to internal magnetic and/or dielectric mechanisms (Silva et al. 2009).

These materials are militarily used to cover vessels and aircrafts surfaces, in order to reduce their radar cross-section and thereby make them more difficult to detect by radars. In the aviation area, the successful use of RAM on the F-117A aircraft, the world's first operational aircraft designed to exploit low-observable stealth technology, can be exemplified, as well as on the B-2 bombers and on the F/A-22 and F-35 aircraft families (Silveira et al. 2017).

\section{METHODOLOGY}

The combustion reaction was carried out in a stainless steel reactor with direct heating, in which iron, zinc, nickel and copper nitrates were mixed as oxidizing reagents and urea as reducing agent. The ratio between the reagents was calculated based on the

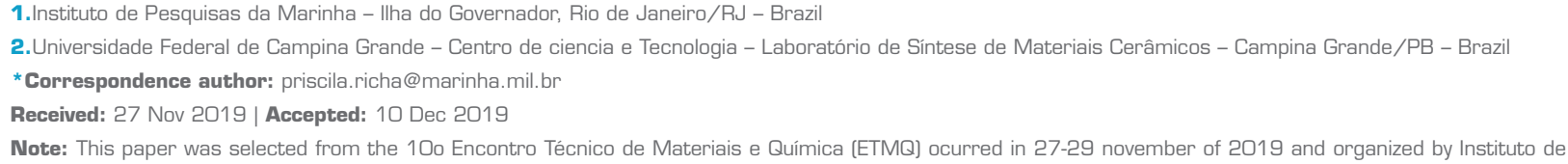


concepts of propellant and explosive chemistry in order to obtain the $\mathrm{Ni}_{0.35} \mathrm{Zn}_{0.35} \mathrm{Cu}_{0.3} \mathrm{Fe}_{2} \mathrm{O}_{4}$ ferrite (Costa and Kiminami 2012). The obtained material was calcined at $1200^{\circ} \mathrm{C}$ for $1 \mathrm{~h}$, deagglomerated in a mortar and then sieved. Composites specimens were prepared with 80:20, 70:30 and 60:40 concentrations in weight of ferrite:polychloroprene. The specimens were analyzed in the following equipment: X-ray diffractometer (XRD), scanning electron microscope (SEM) and a network vector analyzer.

\section{RESULTS}

Subsequently, the analysis of the 80:20 composite by X-ray diffraction (Fig. 1) and the scanning electron microscopy (Fig. 2) are presented.

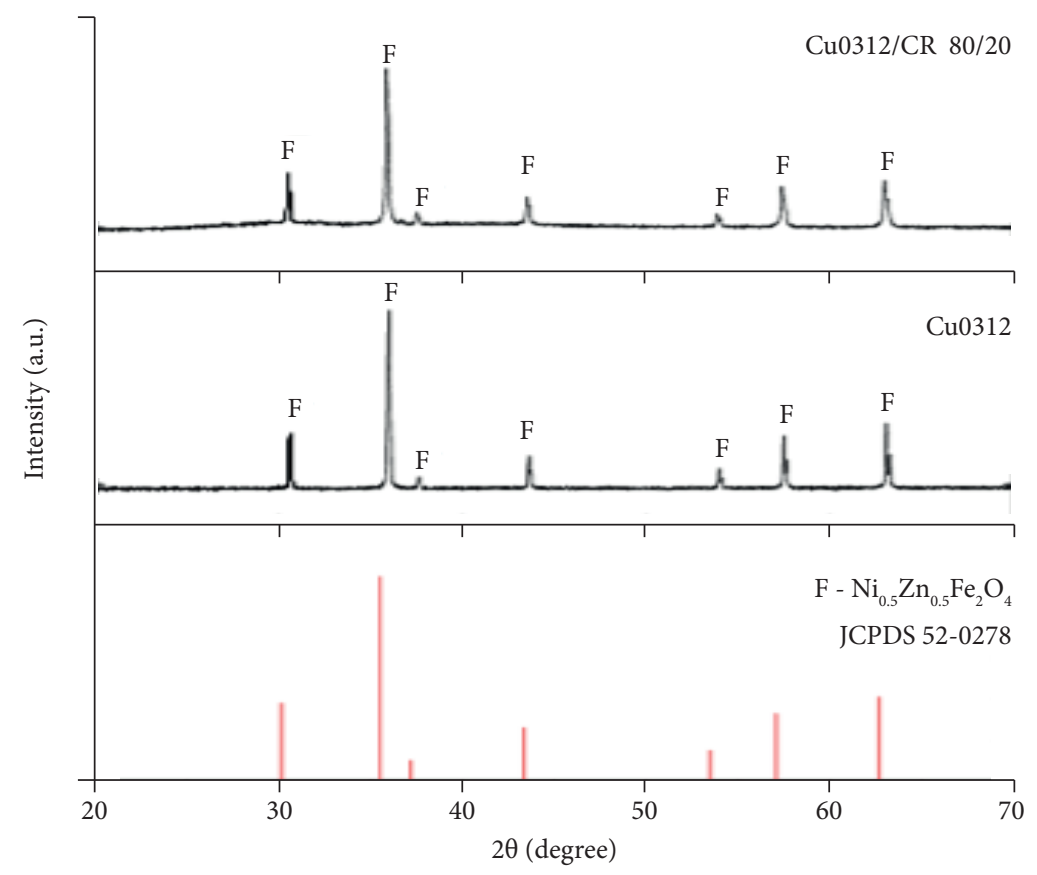

Figure 1. X-ray diffractogram of the pure ferrite and the 80:20 composite.

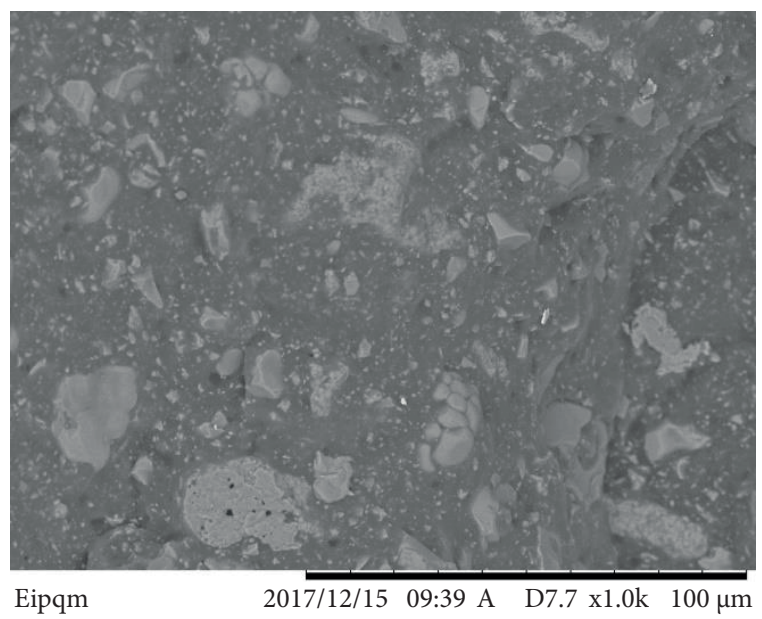

Figure 2. Photomicrograph of the 80:20 composite with $500 \times$ magnification. 
The diffractogram shows the single phase formation of the Ni-Zn spinel ferrite (JCPDS 52-0278). In the photomicrograph, a homogeneous distribution of the ferrite in the polychloroprene can be observed, demonstrating that the matrix acted as a good dispersing medium for the magnetic particles, which have a high tendency to agglomerate.

Figure 3 shows the real and imaginary permittivities of the composites, while Fig. 4 shows the real and imaginary permeabilities, both in the frequency range of 8.2 to $12.4 \mathrm{GHz}$ (X-band).

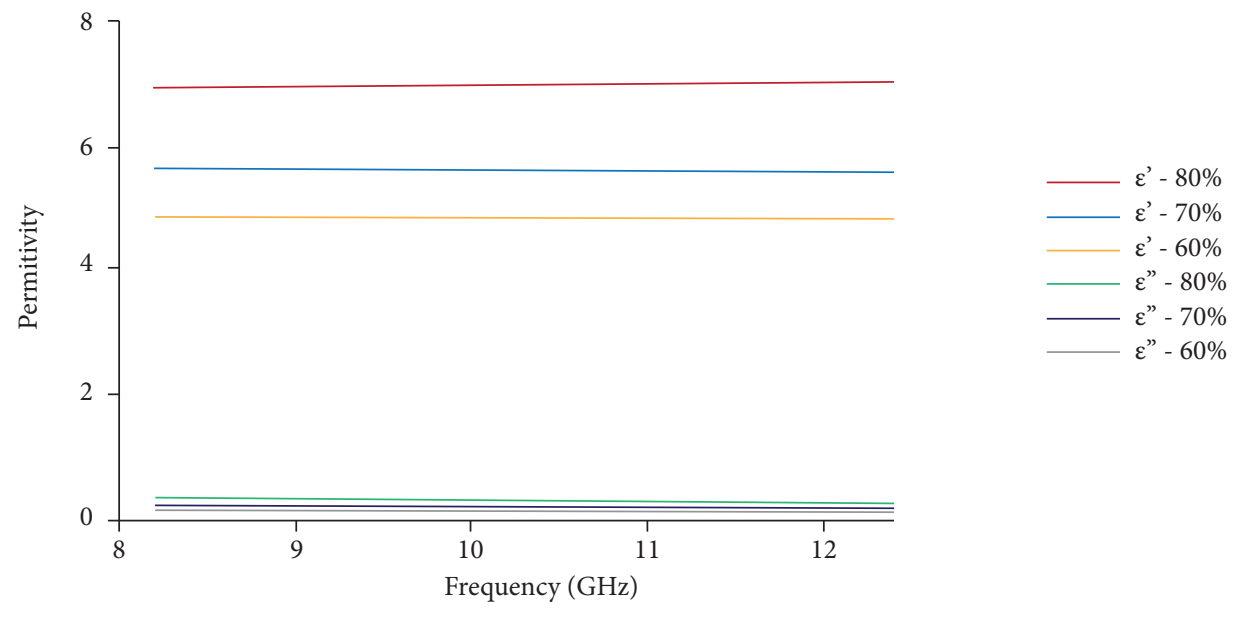

Figure 3. Real $\left[\varepsilon^{\prime}\right]$ and imaginary [ $\varepsilon$ ") permittivities of the composites.

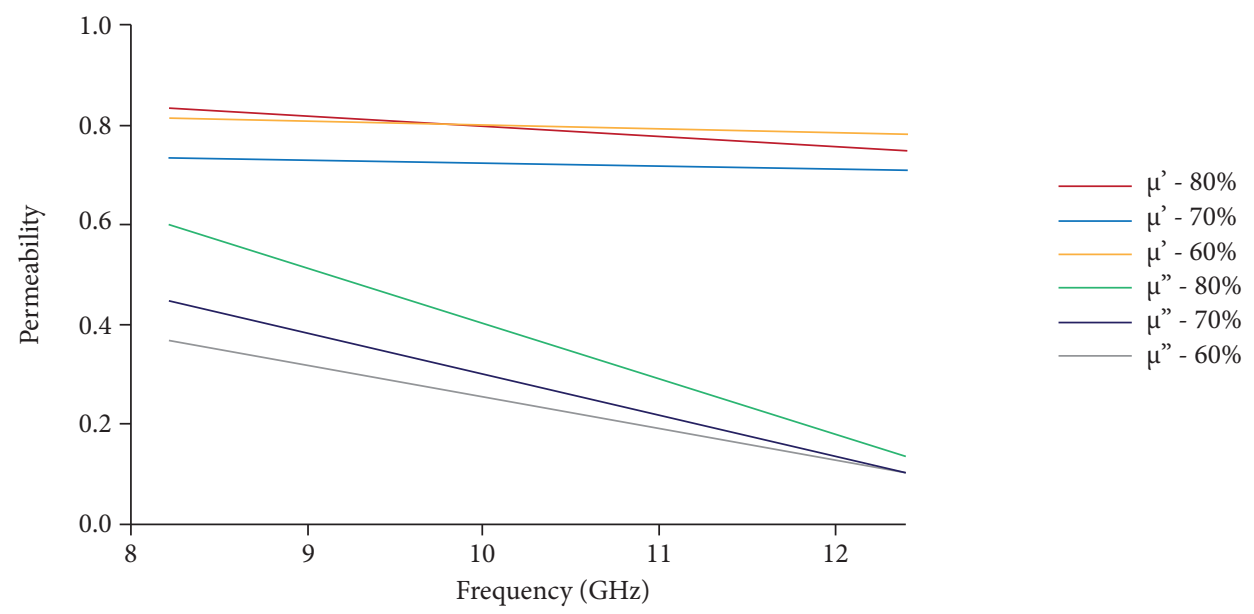

Figure 4. Real ( $\left.\mu^{\prime}\right)$ and imaginary ( $\mu$ ") permeabilities of the composites.

The values of real and imaginary permittivities remained almost constant for the entire analyzed frequency range, presenting only few variations that can be better observed by the dielectric loss factor of the composites (Fig. 5). The real part of permeability shows a small decay with increasing frequency, while the imaginary part of permeability shows a more pronounced decay. Figure 6 shows the magnetic loss factor of the composites along the $\mathrm{X}$ band.

Figures 5 and 6 show that the higher the percentage of ferrite in the composite, the higher the dielectric and magnetic losses, however, the losses are reduced with increasing frequency. The composites presented low values of dielectric losses compared to the magnetic losses, indicating that the electromagnetic wave attenuation is mainly attributed to magnetic mechanisms.

The following graphics present the reflectivity versus the frequency for the 80:20 (Fig. 7), the 70:30 (Fig. 8) and the 60:40 (Fig. 9) composites with different thicknesses. 


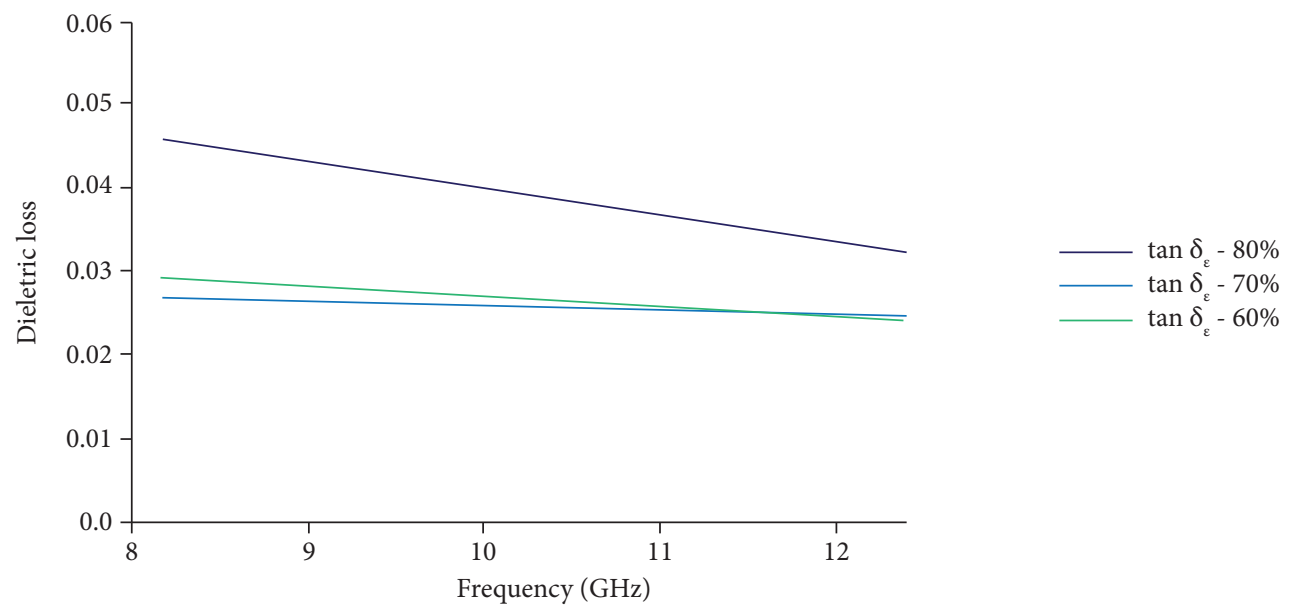

Figure 5. Dielectric loss factor $[\tan \delta \varepsilon$ ) of the composites.

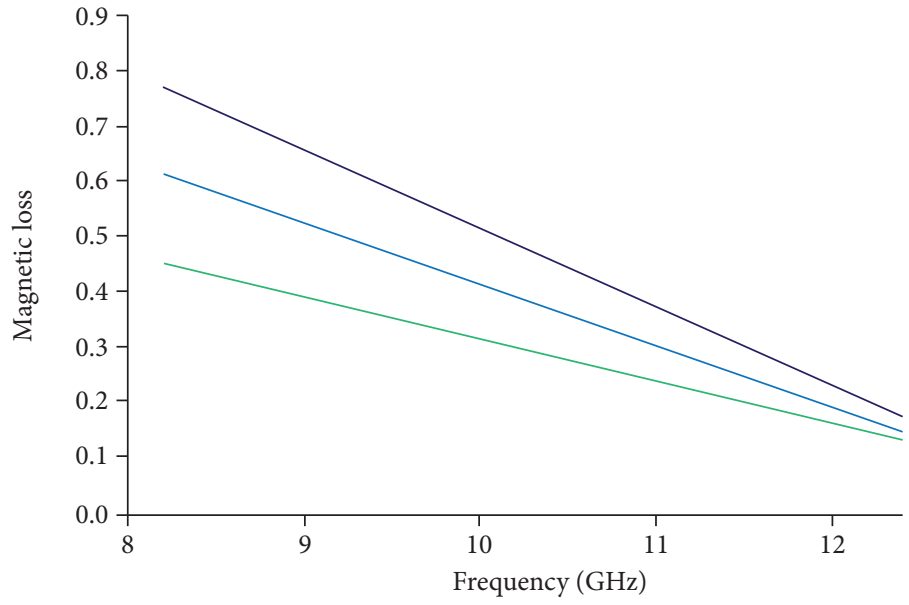

$\tan \delta_{\mu}-80 \%$ $\tan \delta_{\mu}-70 \%$ $\tan \delta_{\mu}-60 \%$

Figure 6. Magnetic loss factor $(\tan \delta \mu)$ of the composites.

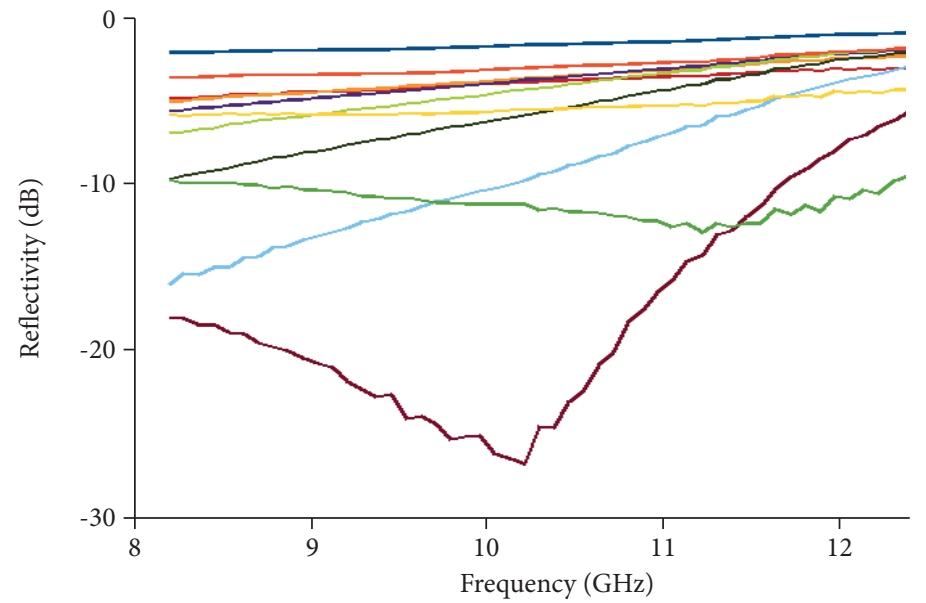

$1.0 \mathrm{~mm}$ $1.5 \mathrm{~mm}$ $2.0 \mathrm{~mm}$ $2.5 \mathrm{~mm}$

$3.0 \mathrm{~mm}$

$3.5 \mathrm{~mm}$

$4.0 \mathrm{~mm}$

$4.5 \mathrm{~mm}$

$5.0 \mathrm{~mm}$

$5.5 \mathrm{~mm}$

$6.0 \mathrm{~mm}$

Figure 7. Reflectivity versus frequency graphic for the 80:20 composite. 


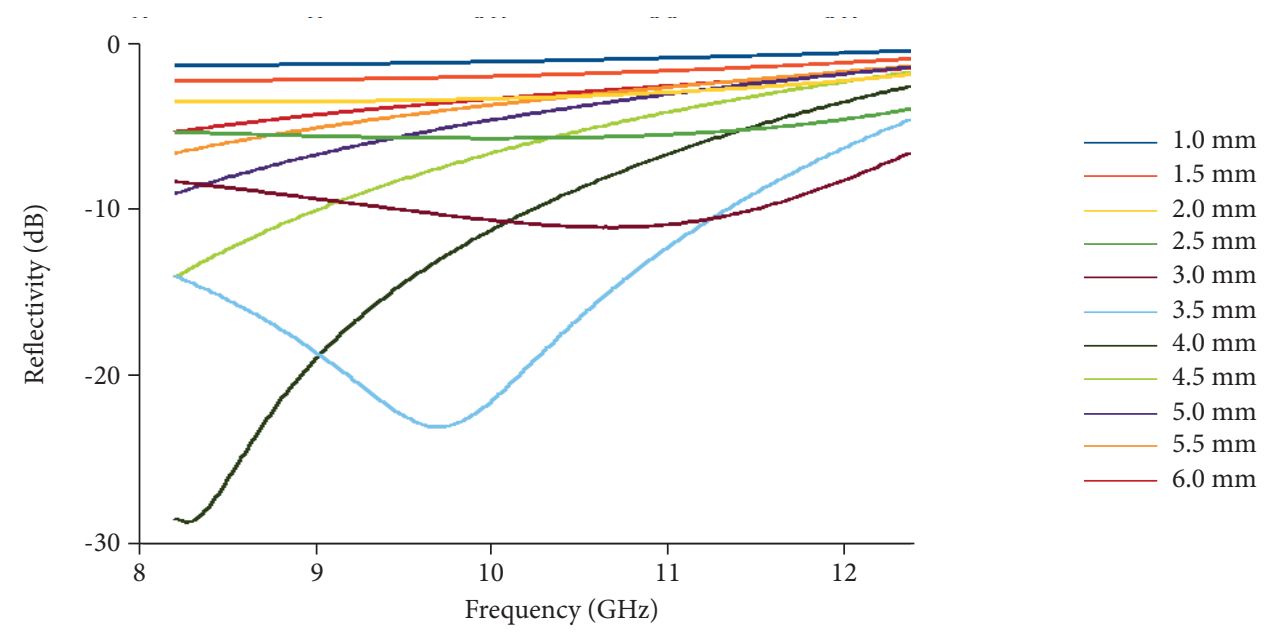

Figure 8. Reflectivity versus frequency graphic for the 70:30 composite.

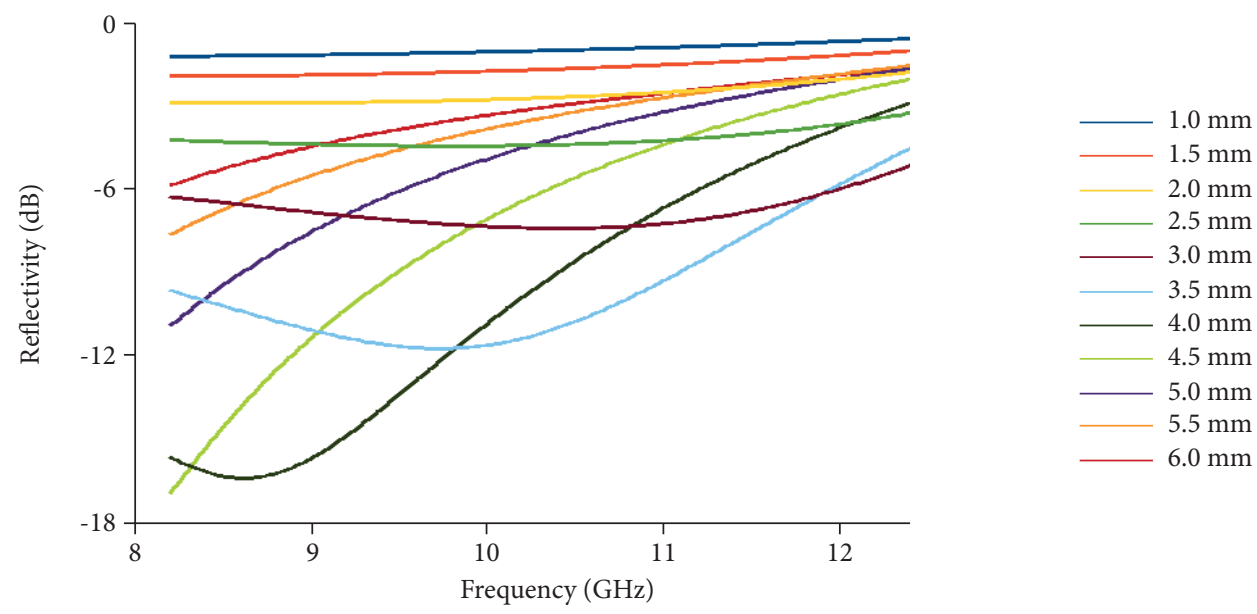

Figure 9. Reflectivity versus frequency graphic for the 60:40 composite.

The higher the ferrite percentage in the composite, the better its performance as a radar-absorbing material. The 80:20 composite showed a reflectivity of $-26.7 \mathrm{~dB}$ at $10.2 \mathrm{GHz}$ for $3 \mathrm{~mm}$ thickness. Additionally, the 80:20 composite showed a reflectivity higher than $-20 \mathrm{~dB}$, from 9 to $10.6 \mathrm{GHz}$ for $3 \mathrm{~mm}$ thickness, which means that it absorbed over $99 \%$ of the incident radiation at this frequency range. The 70:30 composite absorbed over $96.9 \%$ (reflectivity higher than $-15 \mathrm{~dB}$ ) of the incident radiation at frequencies between 8.4 and $10.6 \mathrm{GHz}$ for $3.5 \mathrm{~mm}$ thickness. While the 60:40 composite absorbed over 90\% (reflectivity higher than -10 $\mathrm{dB}$ ) of the incident radiation at frequencies from 8.4 to $10.8 \mathrm{GHz}$ for $3.5 \mathrm{~mm}$ thickness.

\section{CONCLUSIONS}

It was observed that the higher the concentration of ferrite in the polychloroprene composite, the better its performance as a radar-absorbing material; on the other hand, there was no standard behavior related to the composites thicknesses. The best performance was observed for the composite with 80:20 concentration in weight of ferrite:polychloroprene, which showed a reflectivity of $-26.7 \mathrm{~dB}$ at $10.2 \mathrm{GHz}$ for $3 \mathrm{~mm}$ thickness. 


\section{FUNDING}

FINEP (Financiadora de Estudos e Projetos) through the contract 09-118-00 with IPqM

\section{AUTHORS' CONTRIBUTION}

All the authors contributed equally to this paper.

\section{REFERENCES}

Costa ACFM, Kiminami RHGA (2012) Dispositivo para produção de nanomateriais cerâmicos em larga escala por reação de combustão e processo contínuo de produção dos nanomateriais. Revista de Propriedade Industrial-RPI 25(01):002181-3.

Silva VA, Pereira JJ, Nohara EL, Rezende MC (2009) Comportamento eletromagnético de materiais absorvedores de micro-ondas baseados em hexaferrita de Ca modificada com íons CoTi e dopada com La. J Aerosp Technol Manag 1(2):255-263. https://doi. org/10.5028/jatm.2009.0102255263

Silveira DC, Gomes N, Rezende MC, Botelho EC (2017) Electromagnetic Properties of Multifunctional Composites Based on Glass Fiber Prepreg and Ni/Carbon Fiber Veil. J Aerosp Technol Manag 9(2):231-240. https://doi.org/10.5028/jatm.v9i2.657 